\title{
Exploring the optimal pre-sintering temperature on compressive strength and anti-fatigue property of graded zirconia-based glass/zirconia structure
}

\author{
Haixin QIAN, Chang CUI, Tingshu SU, Fuqiang ZHANG and Jian SUN \\ Department of Prosthodontics, Ninth People's Hospital, Shanghai Jiao Tong University School of Medicine, Shanghai Key Laboratory of Stomatology, \\ Shanghai 200011, China \\ Corresponding author, Jian SUN; E-mail: doctorsunjian74@aliyun.com
}

\begin{abstract}
To explore the optimal pre-sintering temperature for graded glass/zirconia material, glass/zirconia specimens were prepared and pre-sintered at $900,1,000$ and $1,100^{\circ} \mathrm{C}$ respectively, glass infiltration and densification at $1,450^{\circ} \mathrm{C}$. Monolith Y-TZP specimens were sintered at $1,450^{\circ} \mathrm{C}$. Nanoindentation was used to test Young's modulus and Hardness. Compressive strength test and cycling fatigue test were conducted. Nanoindentation test showed graded change of Young's modulus in glass/zirconia structure. The compressive strength and the number of cycles to failure of specimens pre-sintered at $1,000^{\circ} \mathrm{C}$ were significantly higher than those of Y-TZP and the specimens pre-sintered at 900 and $1,000^{\circ} \mathrm{C}(p<0.05)$. It is concluded that when the pre-sintering temperature is set at $1,000^{\circ} \mathrm{C}$, the graded glass/zirconia structure exhibits the most optimal compressive strength and anti-fatigue property.
\end{abstract}

Keywords: Graded glass/zirconia, Pre-sintering temperature, Compressive strength, Anti-fatigue property

\section{INTRODUCTION}

Using a strong zirconia core material supporting a weaker porcelain veneer to reach a more excellent strength for wide indications is the effort that has been continuously made. However, the fracture rate is approximately $1-3 \%$ each year ${ }^{1)}$. In addition of fracture problem, veneered zirconia cannot be readily adhesively bonded to dentine due to a dense, high purity crystalline structure at the bonding surface. These problems motivated us to develop novel damage resistant, easy to cement, and ultra strong glass/zirconia structures for all-ceramic prostheses. The bio-inspired design concept has been recently introduced to the development of new all-ceramic materials. The synthetic functionally graded material (FGM) architectures have been proved to significantly reduce stress concentration at the interface and toughen all-ceramic restorations s.7). $^{2-7}$.

The synthetic procedure involves pre-sintering zirconia core and glass infiltration. The pre-sintering procedure can produce porous template for glass infiltration. It has been proved that temperature can influence the microstructure of zirconia template, which inevitably will influence the mechanical property. Therefore pre-sintering temperature may influence the mechanical property of functionally graded material. The present study aims to explore the optimal pre-sintering temperature for graded glass/zirconia material.

\section{MATERIALS AND METHODS}

\section{Materials}

Zirconia compacts were formed from a fine size yttriastabilized zirconia powder $\left(5.18 \mathrm{wt} \% \mathrm{Y}_{2} \mathrm{O}_{3}\right.$, TZ-3Y-E grade, Tosoh, Tokyo, Japan) using a cold isostatic press at $200 \mathrm{MPa}$. A family of glass in the $\mathrm{SiO}_{2}-\mathrm{Al}_{2} \mathrm{O}_{3^{-}}$ $\mathrm{K}_{2} \mathrm{O}-\mathrm{Na}_{2} \mathrm{O}-\mathrm{CaO}-\mathrm{Tb}_{4} \mathrm{O}_{7}$ system has been developed to infiltrate Y-TZP. The main composition ( $>1 \mathrm{wt} \%)$ of the infiltrating glass contained: $\mathrm{SiO}_{2}(65.5 \mathrm{wt} \%), \mathrm{Al}_{2} \mathrm{O}_{3}$ (11.7 wt $\%), \mathrm{K}_{2} \mathrm{O}$ (10.0 wt\%), $\mathrm{Na}_{2} \mathrm{O}$ (7.3 wt\%), $\mathrm{CaO}(3.0$ wt\%), and $\mathrm{Tb}_{4} \mathrm{O}_{7}(1.9 \mathrm{wt} \%)$. The coefficient of thermal expansion (CTE) of the selected glass composition was around $10.4 \times 10^{-6 \circ} \mathrm{C}^{-1}$, from 25 to $450^{\circ} \mathrm{C}$ similar to that of Y-TZP $\left(10.5 \times 10^{-60} \mathrm{C}^{-1}\right.$, from 25 to $\left.450^{\circ} \mathrm{C}\right)$.

The compacts were divided into four groups. To produce monolith Y-TZP, one group was sintered at $1,450^{\circ} \mathrm{C}$ for $2 \mathrm{~h}$ inside a high temperature box air furnace, cooling at room temperature. To produce graded structures, other three groups were pre-sintered at $900,1,000$ and $1,100^{\circ} \mathrm{C}$ for $1 \mathrm{~h}$ in air respectively, producing a porous template for glass infiltration. The surfaces of pre-sintered Y-TZP were coated with slurry of the aforementioned powdered glass composition. Glass infiltration and densification were carried out simultaneously at $1,450^{\circ} \mathrm{C}$ for $2 \mathrm{~h}$ in air. All specimens of $\mathrm{G} / \mathrm{Z}$ were subjected to hydrofluoric acid (HF, 10\%) etching for $15 \mathrm{~min}$ to remove outer surface residual glass layer, then to anhydrous ethanol for $180 \mathrm{~s}$ for ultrasonic cleaning and dried.

\section{Characterization}

\section{SEM microstucture}

Microstructure of G/Z specimens were examined by a scanning electron microscopy (SEM) (JSM-6700F, JEOL, Tokyo, Japan). Specimens were sectioned using a linear precision saw (IsoMet4000, Buehler, Lake Bluff, IL, USA). The cross-sections were polished to $1 \mu \mathrm{m}$ finish, then ethanol cleaned and carbon coated. Backscattered electron (BSE) image was captured using energy dispersive spectrometer under $15 \mathrm{kv}$ circumstance.

\section{Nanoindentation test}

Young's modulus and hardness of the residual glass layer, the graded glass-zirconia (G/Z) layer and the 
Y-TZP interior were measured using nanoindentations (G200, Keysight technologies, Santa Rosa, CA, USA) with a Vickers indenter. Measurements were made on the polished cross-sections of G/Z at a maximum load of $200 \mathrm{mN}$ to produce a penetration depth of $\sim 300 \mu \mathrm{m}$ in the dense Y-TZP and $\sim 100 \mu \mathrm{m}$ in the glass regions, respectively. The glass region was chosen as the starting point, carried out each test with a step size of $25 \mu \mathrm{m}$ toward zirconia region and mapped a curve according to the results of each indentation.

\section{Compressive strength test}

Testing model for compressive strength was a G/Z/ polycarbonate substrates which is made of $\mathrm{G} / \mathrm{Z}$ plate bonded epoxy resin onto polycarbonate substrates. The resin base had a elastic modulus very close to dentine. The G/Z plate had a thickness of $0.5 \mathrm{~mm}$ and a diameter of $5 \mathrm{~mm}$. The polycarbonate substrate had a thickness of $4 \mathrm{~mm}$ and a diameter of $5 \mathrm{~mm}$ and the thickness of the epoxy adhesive interlayer was $\sim 20 \mu \mathrm{m}$. For the present study, the thickness of the epoxy resin is not critical, because the Young's modulus of epoxy resin is similar to that of the polycarbonate base ${ }^{8)}$. Polycarbonate was selected as a support material for the ceramic plates because it is compliant and can be considered a representative for dentin or bone. Specimens were divided to 4 groups: monolith Y-TZP bonded with resin base, graded $\mathrm{G} / \mathrm{Z}$ plate at three different pre-sintering temperature $\left(900,1,000\right.$, and $\left.1,100^{\circ} \mathrm{C}\right)$ bonded with resin base. Six specimens were fabricated for each group. The test was carried out on material testing system (EZ20, AMETEK, Berwyn, PA, USA). A One-way ANOVA (SAS 9.13) was used to analysis the compressive strength, A LSD test was used to compare the difference between each group. Significance level was set at 0.05 .

\section{Cycling fatigue test}

The samples were prepared and grouped as same as in the compressive strength test. Sine-curve axial loading tested samples on a fatigue test machine (ELECTROFORCE, 3330, BOSE, Framingham, MA, USA) for 100,000 times or until fracture. Loading magnitude was set at $-60 \sim-600 \mathrm{~N}$ and $-100 \sim-1,000 \mathrm{~N}$, with a frequency of $5 \mathrm{~Hz}$. Number of cycles to failure at different pre-sintering temperature was compared. A One-way ANOVA (SAS9.13, SAS Institute, Cary, $\mathrm{NC}$, USA) was used to analysis the cycling times, A Bonferroni test was used to compare the difference between each group. Significance level was set at 0.05.

\section{RESULTS}

SEM images of G/Z specimens were shown in Fig.1. Three distinctive zones were apparent: an outer surface residual glass layer, a graded glass-zirconia layer, and a dense Y-TZP interior. The outer surface residual glass layer as shown in a low magnification backscattered electron (BSE) image was dark phase. The dense Y-TZP interior was light phase. The graded G/Z layer was in between the dark phase and the light phase with a thickness of $110 \pm 10 \mu \mathrm{m}$ (mean \pm S.D.).

The dependence of Young's modulus and hardness on depth of G/Z was shown in Fig. 2. The residual glass layer $(\mathrm{d} \approx 100 \mu \mathrm{m}$, marked as zone I in Fig. 2) possessed a Young's modulus value of $80.08 \pm 4.39 \mathrm{GPa}$ and a hardness value of $7.8 \pm 0.73 \mathrm{GPa}$. From the testing point in G/Z region(labeled as zone II in Fig. 2), Young's modulus value and hardness value gradually increased

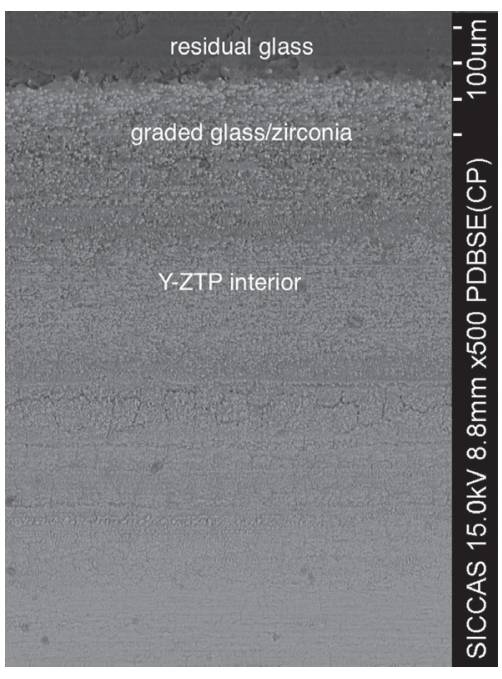

(a)

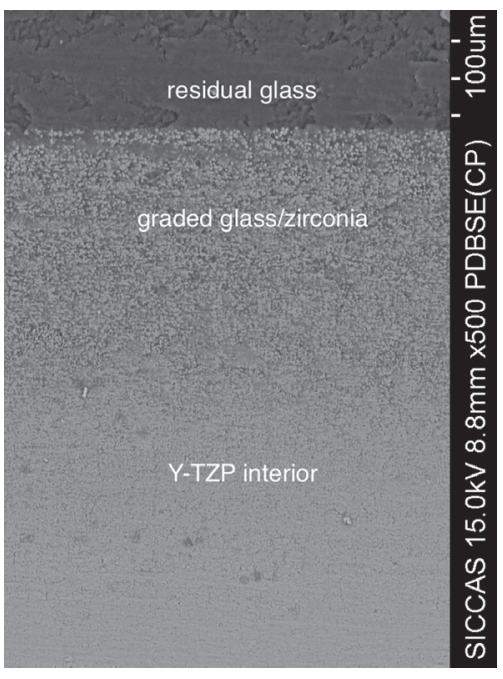

(b)

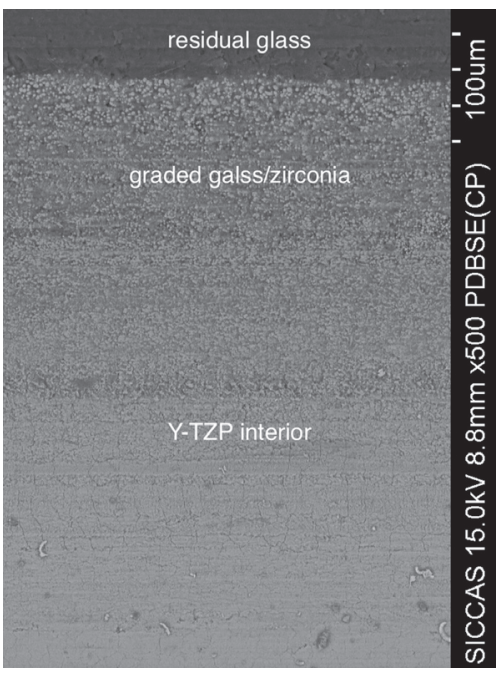

(c)

Fig. 1 The surface of glass/zirconia specimen.

(a) the surface of glass/zirconia specimen pre-sintered at $900^{\circ} \mathrm{C}$. (b) the surface of glass/zirconia specimens pre-sintered at $1,000^{\circ} \mathrm{C}$. (c) the surface of glass/zirconia specimens pre-sintered at $1,100^{\circ} \mathrm{C}$. 


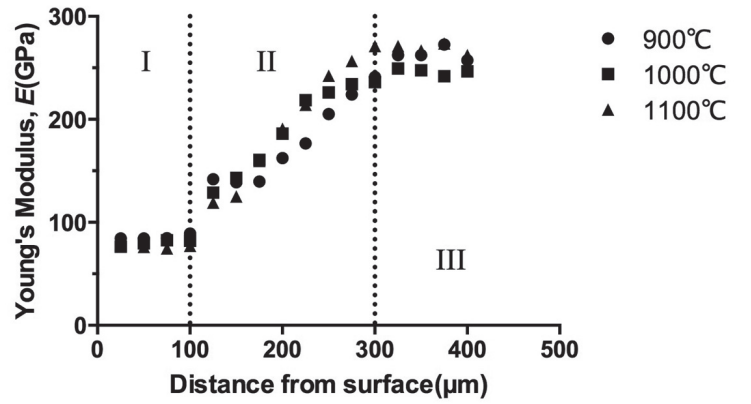

(a)

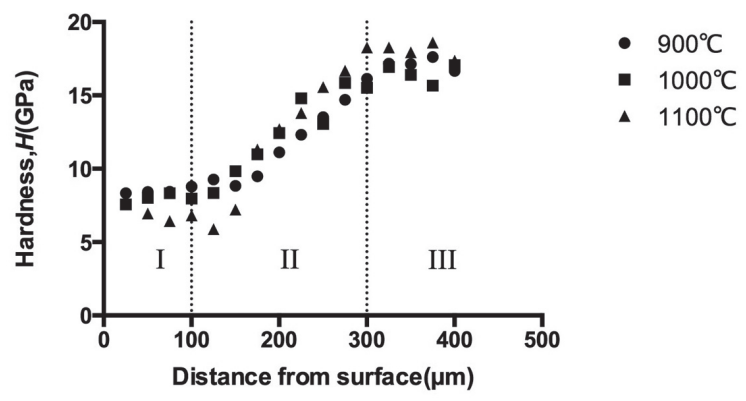

(b)

Fig. 2 Variations of (a) Young's modulus $E$ and (b) hardness $H$ as a function of depth $z$ below the G/Z surface.

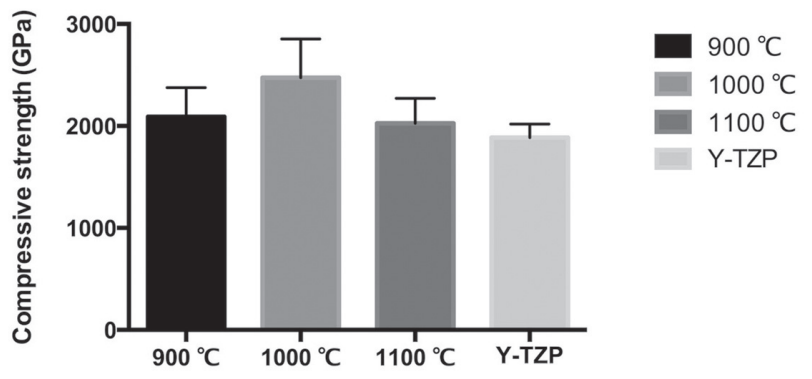

Fig. 3 Compressive strength of specimens in different groups.

from $129.9 \pm 11.48 \mathrm{GPa}$ and $7.82 \pm 0.73 \mathrm{GPa}$ near the residual glass/graded layer interface to $249.5 \pm 18.82 \mathrm{GPa}$ and $16.63 \pm 1.44 \mathrm{GPa}$ near the interior graded layer $/ \mathrm{Y}$ TZP interior boundary. As shown in Fig. 3, compressive load of $\mathrm{G} / \mathrm{Z}$ specimens pre-sintered at $1,000^{\circ} \mathrm{C}$ was $2,473.35 \pm 381.03 \mathrm{GPa}$, significantly higher than those of $900^{\circ} \mathrm{C}, 2,090.13 \pm 286.81 \mathrm{GPa}(p<0.05), 1,100^{\circ} \mathrm{C}$, $2,025.9 \pm 244.77 \mathrm{GPa}(p<0.01)$, and monolith Y-TZP, $1,886.38 \pm 133.24 \mathrm{GPa}(p<0.01)$. Compared to monolith Y-TZP, the load of specimens pre-sintered at 900 and $1,100^{\circ} \mathrm{C}$ was higher than the value of monolith Y-TZP but with no statistical differences $(p>0.05)$, nor between the value of 900 and $1,100^{\circ} \mathrm{C}(p>0.05)$.

Cycling fatigue test results in Fig. 4 revealed the number of cycles to failure was different among groups when specimens loaded at $-100 \sim 1,000 \mathrm{~N}$. The number of specimens at 900 and $1,000^{\circ} \mathrm{C}$ was $(55 \pm 0.45) \times 10,000$ times, and $(55 \pm 0.63) \times 10,000$ times, respectively, 50,000 times higher than that of $1,100^{\circ} \mathrm{C}(p<0.05)$, and 75,000 times higher than that of monolith Y-TZP $(p<0.01)$. There was no difference between the value of $900^{\circ} \mathrm{C}$ and $1,000^{\circ} \mathrm{C}(p>0.05)$, nor between the value of $1,100^{\circ} \mathrm{C}$ and Y-TZP $(p>0.05)$. When the load at $-60 \sim 600 \mathrm{~N}$, all specimens remained intact.

\section{DISCUSSION}

Many efforts have been made to investigate the way

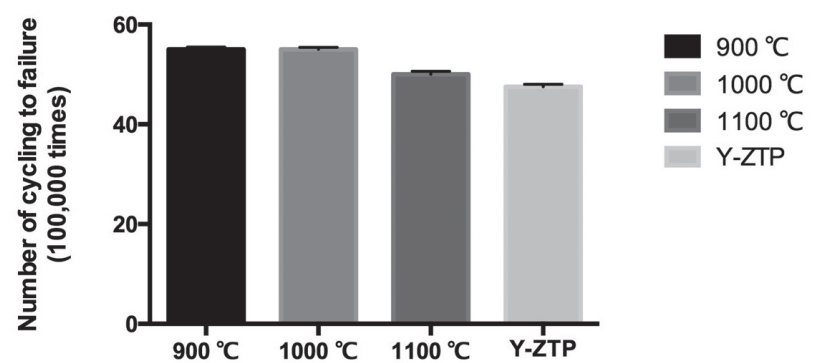

Fig. 4 Number of cycles to fracture of specimens in different groups loaded at $-100 \sim 1,000 \mathrm{~N}$.

by which the pre-sintering temperature influence the mechanical properties and machinability of homogenous Y-TZP, but little has been devoted to the pre-sintering temperature of functionally graded glass-zirconia structure.

The TZ-3Y-E grade zirconia powder used in the present study has been used world widely for ceramic restoration, and other study has also use this powder as assessed material ${ }^{9}$. Although some other commercial zirconia may have different composition and property, and the results may not be generalized to full extent, the implication of this study could be useful to most dentists and technicians.

Elastically graded glass/zirconia (G/Z) structures may be produced by infiltrating the surfaces of heattreated zirconia templates with a silica-based glass ${ }^{8)}$. The merits of such an approach lie in a relatively low heat-treatment temperature for zirconia templates (compared to the sintering temperature of zirconia), and in combining glass infiltration and zirconia densification into a single process ${ }^{9,10)}$. This way the glass infiltration depth can be tailored by manipulating the porosity of the zirconia templates and the grain growth and/or destabilizing of the tetragonal zirconia phase associated with the post-sintering heat-treatment can be prevented ${ }^{11)}$. So the surface flaw by post-sintering heat-treatment can be eliminated and G/Z structure exhibits better resistance to damage than homogeneous 
Y-TZP. Present study showed there was a grade G/Z structure after glass infiltration followed pre-sintering the zirconia template. This infiltration treatment produced a depth-dependence variation of the Young's modulus and hardness of G/Z plate, which was nearly consistent with the elastic modulus distribution in dentin-enamel junction (DEJ), and had an noticeable effect on mechanical properties. The graded G/Z structure exhibited higher compressive strength compared to the controlled homogeneous Y-TZP, and the number of cycles to failure of the graded structure also increased.

Pre-sintering temperature can influence the microstructure of zirconia template, which inevitably will influence the mechanical property ${ }^{12,13)}$. Therefore it is possible that pre-sintering temperature can influence the mechanical behavior of graded $\mathrm{G} / \mathrm{Z}$ structure. The G/Z structure pre-sintered at $1,000^{\circ} \mathrm{C}$ exhibited the highest compressive strength and number of cycles to failure over those structures presintered at 900 and $1,100^{\circ} \mathrm{C}$. Pre-sintering is essential to densification of zirconia core material, which can improve the machinability and mechanical properties of zirconia ceramic. After pre-sintering, there is certain porosity inside the zirconia template, which can facilitate glass infiltration. With the rising of pre-sintering temperature, zirconia template becomes denser and the porosity reduced, thus impacting infiltration, and eventually influencing the mechanical properties of the graded structure.

A limitation of this study was that only one commercial zirconia was used, and the results may not apply to other commercial materials, which means study on other commercial zirconia be required to explore the procedure for those materials. Meanwhile, study on actual dental crown structure should be done to explore the optimal procedure of fabricating functionally graded glass/zirconia structure.

\section{CONCLUSION}

Results of present study reveal that design of functionally graded glass/zirconia structure has a beneficial influence on mechanical properties. The pre- sintering temperature influences mechanical properties of graded structure. When the pre-sintering temperature is set at $1,000^{\circ} \mathrm{C}$, the graded glass/zirconia of structure exhibits the most optimal compressive strength and anti-fatigue property.

\section{REFERENCES}

1) Burke FJ, Fleming GJ, Nathanson D, Marquis PM. Are adhesive technologies needed to support ceramics? An assessment of the current evidence. J Adhes Dent 2002; 4: $7-22$.

2) Huang M, Wang R, Thompson V, Rekow D, Soboyejo WO. Bioinspired design of dental multilayers. Mater Sci Eng A 2007; 464: 315-320.

3) Niu X, Rahbar N, Farias S, Soboyejo W. Bio-inspired design of dental multilayers: experiments and model. J Mech Behav Biomed Mater 2009; 2: 596-602.

4) Zhang Y, Ma L. Optimization of ceramic strength using elastic gradients. Acta Mater 2009; 57: 2721-2729.

5) Kim JW, Liu L, Zhang Y. Improving the resistance to sliding contact damage of zirconia using elastic gradients. J Biomed Mater Res B Appl Biomater 2010; 94: 347-352.

6) Zhang Y, Chai H, LawnBR. Graded structures for all-ceramic restorations. J Dent Res 2010; 89: 417-421.

7) Ren L, Liu L, Bhowmick S, Gerbig YB, Janal MN, Thompson VP, Zhang Y. Improving fatigue damage resistance of alumina through surface grading. J Dent Res 2011; 90: 1026-1030.

8) Zhang Y, Lawn B. Long-term strength of ceramics for biomedical applications. J Biomed Mater Res B Appl Biomater 2004; 69: 166-172.

9) Zhang Y, Kim JW. Graded structures for damage resistant and aesthetic all-ceramic restorations. Dent Mater 2009; 25: 781-790.

10) Zhang Y, Ma L. Optimization of ceramic strength using elastic gradients. Acta Mater 2009; 57: 2721-2729.

11) Piascik JR, Thompson JY, Bower CA, Stoner BR. Stress evolution as a function of substrate bias in rf magnetron sputtered yttria-stabilized zirconia films. J Vac Sci Technol A 2006; 24: 1091-1095.

12) Ebeid K, Wille S, Hamdy A, Salah T, El-Etreby A, Kern M. Effect of changes in sintering parameters on monolithic translucent zirconia. Dent Mater 2014, 30: e419-e424.

13) Inokoshi M, Zhang F, De Munck J, Minakuchi S, Naert I, Vleugels J, Van Meerbeek B, Vanmeensel K. Influence of sintering conditions on low-temperature degradation of dental zirconia. Dent Mater 2014; 30: 669-678. 